\title{
No Evidence of Disease Activity after Five Years of Autologous Hematopoietic Stem Cell Therapy for Multiple Sclerosis: Detailed Report of Five Patients
}

\author{
Comini-Frota $\mathrm{ER}^{1^{*}}$, Marques $\mathrm{BCC}^{2}$, Torres $\mathrm{C}^{2}$, Bliacheriene $\mathrm{JS}^{2}$, Cohen $\mathrm{KMS}^{2}$, Maciel $\mathrm{PP}^{2}$ and \\ Rucki $S^{1}$ \\ ${ }^{1}$ Professor of Medicine at Universidade José do Rosário Vellano, Vellano, Rua Lïbano 66 Itapoã, Belo Horizonte, MG, Brazil \\ ${ }^{2}$ Medical Student at Universidade José do Rosário Vellano, Horizonte, MG, Brazil
}

*Corresponding author: Comini-Frota ER, Professor of Medicine at Universidade José do Rosário Vellano, Rua Lïbano 66 Itapoã, Belo Horizonte, MG, Brazil, Tel: 5531992940600, E-mail: elizcomini@gmail.com

Citation: Comini-Frota ER, Marques BCC, Torres C, Bliacheriene JS, Cohen KMS, et al. (2018) No Evidence of Disease Activity after Five Years of Autologous Hematopoietic Stem Cell Therapy for Multiple Sclerosis: Detailed Report of Five Patients. J Neurosci Neuropsyc 2: 201. doi: 10.18875/2577-7890.2.201

Article history: Received: 02 July 2018, Accepted: 03 July 2018, Published: 05 July 2018

\begin{abstract}
Background: Multiple sclerosis (MS) is an immune-mediated disease of the central nervous system. Its treatment has focused on inflammation control as early as possible to avoid disability. Autologous hematopoietic stem cell transplantation (AHSCT) has been used for treating MS since 1996 without decisive results regarding benefits or long-term efficacy. We report the follow-up of five patients who were evaluated for up to five years after the stem cell transplantation treatment and who did not present any disease activity.
\end{abstract}

Methods: Five patients followed up at an MS center in Belo Horizonte, Brazil, who had relapsing-remitting MS with high disease activity, underwent AHSCT from 2009 to 2011. They were evaluated clinically, with magnetic resonance imaging, and by the Expanded Disability Status Scale, every six months and up to five years after transplantation.

Results: The patients in our study comprised four women and one man, with age ranging from 25 to 50 years, and time since disease onset ranging from 4 to 17 years at the time of the procedure. Four patients improved, one patient was stabilized, and all patients continued to be free of disease activity after 5 years.

Discussion: Through improving patient selection and decreasing the time since disease onset, AHSCT could stop epitope spreading and disease progression. Despite multiple other therapeutic choices, AHSCT is a treatment to consider for aggressive MS disease.

Keywords: Stem cell; Autologous Transplant; Multiple Sclerosis Treatment; NEDA

\section{Introduction}

Multiple sclerosis (MS) is the most prevalent chronic inflammatory disease that affects the central nervous system (CNS) and is considered to be the prototype disease immune-mediated by auto-reactive $\mathrm{T}$ cell [1]. Inflammatory reaction targeting self CNS myelin and axonal proteins evolves to demyelination and degeneration in multiple areas of white and gray matter, which leads to progressive disability in genetically susceptible young people [2]. The most common symptoms are progressive paralysis, sensibility disorder vision loss, coordination disability, and cognitive impairment [3].

The pathophysiology currently accepted is that myelin-reactive $\mathrm{T}$ cells are activated in the peripheral circulation or peripheral lymph nodes by antigens with which susceptible hosts had been in contact, possibly during childhood, constituting a breach of auto-tolerance to CNS antigen [1]. Later, these T cells cross the blood-brain barrier and encounter the myelin antigen in the CNS parenchyma, presented by activated microglia, starting an inflammatory response that causes myelin destruction and axon degeneration [1]. As other antigens become exposed through cell destruction, epitope spreading or activation of T cells against multiple other antigens occurs, and the inflammation is thus perpetuated in the inflammatory reaction. Axonal damage and epitope spreading from the outset are two current concepts that support the urgency of early and effective treatment [4]. 
The evidence for inflammation and degeneration in MS has three major parameters: clinical presentation of intermittent neurological deficits (relapses); appearance and accumulation of lesions seen through magnetic resonance imaging (MRI) as gadolinium-enhanced lesions or new T2-weighted hyperintense lesions, respectively; and progression of disability, as measured by the Expanded Disability Status Scale (EDSS) [5,6]. These three parameters (clinical presentation, MRI, and EDSS) taken together are considered evidence for disease activity and have been recently referred to as a composite named No Evidence of Disease Activity (NEDA) and are promising targets for clinical trials [7].

There are currently many disease-modifying drugs in MS, all of them focused on inflammation control [2]. The impact of these therapies on MS activity and progression has supported the evidence of an immune-mediated disease [3]. Otherwise, none of the treatments, even the most effective immunosuppression, has been reported to help maintain long-term control of disease progression [2]. Furthermore, the treatments that imposed periods of selective or systemic immunosuppression have high risks of infection and malignant diseases.

Stem cell transplantation enables resetting of the hematopoietic linkage, and the rationale for this treatment in MS is that it renews the immune system and stops disease progression [7]. Since 1996, when autologous hematopoietic stem cell transplantation (AHSCT) started to be used for treating MS, more than 700 patients with MS have undergone this treatment [7]. In most of these cases, other available treatments had failed or there was evidence of highly active disease [8-10].

Patient selection has improved since the beginning. Today, enough knowledge and experience have been accrued to include mainly patients with high disease activity, with less time since disease onset, and without any response to any other medication [10]. No controlled studies have yet been conducted because of the implicit difficulty of implementing a placebo arm or a blind evaluation within such studies [9].

Stem cell therapy involves mobilization of stem cells from the medulla to the peripheral circulation, harvesting of the stem cells, maintenance in appropriate storage, and immunoablation. Immunoablation may be performed either with ablative or no ablative therapy, such as use of cyclophosphamide or, more recently, use of monoclonal antibodies, anti-CD52, alemtuzumab, and then reinfusion of non-selected stem cells [8].

\section{Methods}

We aim to report on five patients who were followed up at a small MS center in Belo Horizonte, MG, Brazil, where 332 patients with MS were treated and followed up personally by the first author. They were referenced to Ribeirao Preto, SP, Brazil, to undergo AHSCT at the university hospital (Hospital das Clínicas, Ribeirão Preto Medical School, University of São Paulo), from January 2009 to April 2011. Eleven patients were selected at the same period for the procedure, however only five had got the funds to support their access because they had to travel and stay in another city far from home. The methods used there for AHSCT have been described elsewhere by the responsible team [7,11]. The five patients were treated with cyclophosphamide (12 g) for a conditioning regimen, a non-ablative therapy, according to the protocol of the transplantation center at the time [11]. After the procedure, the patients returned to the original MS center and were evaluated every six months up to December 2015, with complete EDSS evaluation, MRI imaging, and clinical examination, by the same neurologist The patients were imaged at baseline and follow-up at the same 1,5T GE ( General Eletric, HDX). The sequences Sagital and Coronal FLAIR T2, Sagital and coronal T1 before and after gadolinium were evaluated by the same radiologist. A total of 50 MRIs and 200 sequences was evaluated and compared. The lesions were counted and measured.

\section{Results}

At the first evaluation at six months after the procedure, four patients presented improved EDSS, and one of them was stabilized. After five years, there were no relapses, no new T2 lesions, no Gad+ lesions, or EDSS progression; this means that they remained with NEDA. Table 1 show the patients' age, age at disease onset, relapses one year before EDSS just before AHSCT, EDSS after one and five years of follow-up, and MRI results. None of the five patients were using any other medication during this follow-up period.

\begin{tabular}{|c|c|c|c|c|}
\hline Name & SSP & CMMM & HSM & AMJM \\
\hline Gender & female & female & male & female \\
\hline Age of first symptoms & 21 & 34 & 4 & 37 \\
\hline Ilness duration & 23 & 4 & 6 & 4 \\
\hline $\begin{array}{c}\text { EDSS at the first } \\
\text { five years of disease } \\
\text { duration }\end{array}$ & 3 & 5 & 9 & 4 \\
\hline $\begin{array}{c}\text { New T2 lesions one } \\
\text { year before treatment }\end{array}$ & 5 & 5 & 8 & 11 \\
\hline $\begin{array}{c}\text { Relapses one year } \\
\text { before treatment }\end{array}$ & 3 & 5 & 6 \\
\hline
\end{tabular}




\begin{tabular}{|c|c|c|c|c|c|}
\hline Name & SSP & CMMM & HSM & AMJM & FSGR \\
\hline $\begin{array}{c}\text { Treatments before } \\
\text { AHSCT }\end{array}$ & $\begin{array}{c}\text { Methylprednisolone/ } \\
\text { Interferon beta/ } \\
\text { cyclosphophamide/ } \\
\text { mitoxantrone }\end{array}$ & $\begin{array}{c}\text { Methylprednisolone/ } \\
\text { Interferon beta/ } \\
\text { glatiramer } \\
\text { acetate/IVIg/ } \\
\text { Cyclophosphamide }\end{array}$ & $\begin{array}{c}\text { Methylprednisolone/ } \\
\text { Interferon beta/ } \\
\text { Cyclophosphamide }\end{array}$ & $\begin{array}{c}\text { Methylprednisolone/ } \\
\text { Interferon beta }\end{array}$ & $\begin{array}{c}\text { Methylprednisolone/ } \\
\text { interferon beta/IVIg }\end{array}$ \\
\hline $\begin{array}{c}\text { Predominant } \\
\text { symptom localization }\end{array}$ & cervical/ & cervical/motor & thoracic/motor & brainstem \\
\hline $\begin{array}{c}\text { EDSS score before } \\
\text { treatment }\end{array}$ & 5.5 & 6.5 & 0 & 0 & 0 \\
\hline $\begin{array}{c}\text { EDSS score five years } \\
\text { after treatment }\end{array}$ & 4.5 & 6 & 0 & 0 & 0 \\
\hline $\begin{array}{c}\text { Relapses five years } \\
\text { after treatment }\end{array}$ & 0 & 0 & 0 & 0 & 0 \\
\hline $\begin{array}{c}\text { MRI activity after } \\
\text { treatment (new T2 } \\
\text { lesions and Gad+) }\end{array}$ & 0 & 0 & & 0 & 0 \\
\hline
\end{tabular}

EDSS: Expanded disability status scale; Gad+: Gadolinium-enhanced lesions; IVIg: Human endovenous immunoglobulin Table 1: Clinical profile of five patients who underwent HSCT, before and 5 years after treatment

At the five-year evaluation, patients were asked about their experience with the ASCT; all the five patients answered that they would undergo the treatment again to be free of disease, if they need to. All of them have signed an informed consent for this report.

\section{Discussion}

Considering that all five patients had high disease activity, these results were a very good outcome for all of them. We continue to follow up those patients and measure disease progression, comparing with other treatments in our center.

In a recent review, Sormani et al. compared the results of two Swedish studies that report the proportion of NEDA patients at fiveyear follow-up cohort after AHSCT, which enrolled 24 and 41 patients, respectively, with the proportion of patients that remained NEDA under other therapies [8]. The proportion of NEDA patients after that treatment were $83 \%$ at 2 years and $60 \%$ at 5 years in one cohort, and $78 \%$ at 2 years and $68 \%$ at 5 years in the other cohort.

Reviewing current treatments such as monoclonal antibodies, in two alemtuzumab and one ocrelizumab studies, the patients that remained NEDA were under 39\% at three-year follow-up [7]. The body of evidence accumulated about AHSCT suggests that this therapy could be more effective to stop disease activity than any other therapy, in a longer follow-up.

Through improving patient selection and decreasing the time since disease onset, AHSCT could stop epitope spreading and disease progression [8].

Treatment with AHSCT has implicit difficulties, given its need for specific facilities and its very restrictive inclusion criteria, but it should be considered in cases of very active disease that do not respond to other treatments. Considering the high cost of the current therapies, and the risk of death through the long-term use of immunosuppressive therapies, AHSCT is still an option for selected patients.

\section{References}

1. Martin R, Sospedra M, Rosito M, Engelhardt B (2016) Current multiple sclerosis treatments have improved our understanding of MS autoimmune pathogenesis. Eur J Immunol 46: 2078-90.

2. Bar-Or A (2008) The immunology of multiple sclerosis. Semin Neurol 28: 29-45.

3. Krieger SC, Cook K, De Nino S, Fletcher M (2016) The topographical model of multiple sclerosis: A dynamic visualization of disease course. Neurol Neuroimmunol Neuroinflamm 3: e279.

4. Dalla Costa G, Passerini G, Messina MJ, Moiola L, Rodegher M, et al. (2015) Clinical significance of the number of oligoclonal bands in patients with clinically isolated syndromes. J Neuroimmunol 289: 62-7.

5. von Gumberz J, Mahmoudi M, Young K, Schippling S, Martin R, et al. (2016) Short-term MRI measurements as predictors of EDSS progression in relapsing-remitting multiple sclerosis: grey matter atrophy but not lesions are predictive in a real-life setting. PeerJ 4: e2442.

6. Kurtzke JF (2008) Historical and clinical perspectives of the expanded disability status scale. Neuroepidemiology 31: 1-9.

7. Sormani MP, Muraro PA, Saccardi R, Mancardi G (2017) NEDA status in highly active MS is easily obtained with autologous hematopoietic stem cell transplantation than other drugs. Mult Scler 23: 201-4.

8. Atkins HL, Bowman M, Allan D, Anstee G, Arnold DL, et al. (2016) Immunoablation and autologous haemopoietic stem-cell transplantation for aggressive multiple sclerosis: a multicentre single-group phase 2 trial. Lancet 388: 576-85.

9. Curro D, Mancardi G (2016) Autologous hematopoietic stem cell transplantation in multiple sclerosis: 20 years of experience. Neurol Sci 37: 857-65.

10. Saccardi R, Freedman MS, Sormani MP, Atkins H, Farge D, et al (2012) European Blood and Marrow Transplantation Group; Center for International Blood and Marrow Research; HSCT in MS International Study Group. Mult Scler 18: 825-34.

11. Rodrigues MC, Hamerschlak N, de Moraes DA, Simoes BP, Rodrigues M, et al. (2013) Guidelines of the Brazilian society of bone Marrow transplantation on hematopoietic stem cell transplantation as a treatment for the autoimmune diseases systemic sclerosis and multiple sclerosis. Rev Bras Hematol Hemoter 35: 134-43. 